\title{
A dupla epidemia: febre amarela e desinformação
}

\author{
Two epidemics: the yellow fever and a lack of information
}

\section{La dupla epidemia: la fiebre amarilla y la falta de información}

Cláudio Maierovitch Pessanha Henriques ${ }^{1, a}$

claudio.henriques@fiocruz.br | https://orcid.org/0000-0002-1461-7082

${ }^{1}$ Fundação Oswaldo Cruz, Gerência Regional de Brasília. Brasília, DF, Brasil.

a Mestrado em Medicina Preventiva pela Universidade de São Paulo.

\section{Resumo}

Esta nota apresenta um breve histórico da origem da febre amarela no Brasil, das medidas de controle e das dificuldades para que orientações de saúde pública cheguem à população. Nela analisam-se alguns episódios de geração de boatos, assim como informações mentirosas e suas consequências muitas vezes danosas. Aponta-se a necessidade de oferecer e divulgar fontes confiáveis para os profissionais e a comunidade, em especial por meio do fortalecimento das instituições e de suas áreas de comunicação social. Assinala-se também a importância do trabalho de campo das equipes de atenção básica, para localizar pessoas expostas a risco, levando-lhes informações e vacinas.

Palavras-chave: febre amarela; epidemia; epizootia; fake news; boatos; desinformação; fontes confiáveis.

\begin{abstract}
This paper presents a brief history of yellow fever origin in Brazil, of the control measures and of the difficulties to the public health guidance to reach the population. It analyzes some cases of rumour propagation, as well as fake information and its often damaging consequences. It points out the need to offer and disseminate reliable sources to professionals and the community, especially through the strengthening of institutions and their areas of social communication. It also highlights the importance of the fieldwork of the primary health care teams, so that they can find people at risk and bring information and vaccines to them.
\end{abstract}

Keywords: yellow fever; epidemic; epizootic; fake news; rumors; lack of information; trusted sources. 


\section{Resumen}

Esta nota presenta una breve historia del origen de la fiebre amarilla en Brasil, de las medidas de control y de las dificultades de las orientaciones de salud pública para llegar a la población. Analiza algunos casos de generación de rumores, así como informaciones falsas y sus consecuencias a menudo perjudiciales. Señala la necesidad de ofrecer y difundir fuentes confiables a los profesionales y a la comunidad, en especial a través del fortalecimiento de las instituciones y sus áreas de comunicación social. También destaca la importancia del trabajo de campo de los equipos de atención primaria de salud, para localizar personas expuestas al riesgo y así llevar a ellas informaciones y vacunas.

Palabras clave: fiebre amarilla; epidemia; epizoótico; fake news; rumores; falta de información; fuentes de confianza.

A saúde é um bom meio de cultura para boatos e rápida circulação de notícias. Isso acontece, em parte, porque a maior parte da população tem pouco conhecimento sobre a área e, em parte, pela ansiedade que causam as notícias sobre doenças e epidemias. $\mathrm{O}$ alastramento é ainda mais rápido quando o assunto é doença grave e ameaçadora.

É positivo que alertas e orientações cheguem logo para todos; entretanto, isso acontece com informações úteis e também com notícias falsas - "fake news", designação em inglês, que tem sido usada também no Brasil. Em contraposição aos objetivos da educação em saúde pública, informações equivocadas podem levar a diversos comportamentos e atitudes geradores de risco, seja pela indução ao uso de tecnologias inadequadas, como medicamentos e vacinas sem indicação, ou, no outro extremo, pela recusa a tecnologias e medidas de proteção necessárias ou ainda pela desorganização que provocam nos serviços de saúde.

A combinação mais perigosa acontece quando informações e orientações que contrariam o conhecimento científico são difundidas numa situação em que existe algum fato real, como uma epidemia ou uma campanha de saúde pública.

As informações sobre a febre amarela já foram objeto de manipulação no passado recente, com consequências desastrosas. A falsa notícia de que havia uma importante epidemia de febre amarela provocou uma corrida em busca da vacina no estado de São Paulo, em 2008, quando na capital do estado foi multiplicado por cinco o número de doses aplicadas, em comparação ao ano anterior. Naquele episódio, quatro pessoas morreram por efeitos adversos graves da vacina ${ }^{1}$.

$\mathrm{Na}$ atual epidemia de febre amarela que o país vive, com os mais exuberantes números de febre amarela silvestre já registrados, problemas semelhantes têm sido comuns. Embora o comportamento dos grandes veículos de comunicação se mantenha equilibrado, nesses dez anos cresceram exponencialmente as redes sociais, dando voz a fontes que antes tinham pouquíssimo alcance.

São muitos os ingredientes que enriquecem a receita. A gravidade da situação atual está representada na quantidade de casos e óbitos - o Brasil confirmou 1.098 casos e 340 óbitos no período de $1^{0}$ julho de 2017 a 20 de março deste ano $^{2}$.

A origem da epidemia estimula a imaginação de muita gente. Há evidências de que a moléstia atingia a população do continente africano antes mesmo da chegada dos invasores europeus. Creditam-se ao flavivírus epidemias que aconteceram em toda a América, nos séculos XVII e XVIII ${ }^{3}$. A teoria aceita é de que o vírus amarílico e seu principal vetor urbano, o mosquito Aedes aegypti, chegaram a este continente a bordo das embarcações que faziam o tráfico de negros que eram vendidos como escravos. Com condições climáticas favoráveis, precária estrutura de saneamento e limpeza além de aglomerações crescentes de pessoas, a doença instalou-se nas cidades. A presença de primatas e mosquitos silvestres - Haemagogus janthinomys e Sabethes leucocelaenus ${ }^{4}$ - receptivos ao vírus, ao lado da intimidade entre ambientes urbanos, rurais e silvestres e do fluxo de pessoas para o interior do país, ofereceram condições ideais para que uma doença 
urbana, importada de outro continente, se instalasse no complexo ambiente das florestas brasileiras, de onde é muito improvável sua eliminação, mesmo num prazo muito longo.

Menos de cem anos nos separam da presença letal da febre amarela urbana em cidades importantes do país. Ela foi considerada, durante dois séculos (XVIII e XIX), a principal doença epidêmica do país, tendo afetado de forma importante as cidades portuárias e, em consequência, o comércio internacional. Alguns dos mais conhecidos sanitaristas brasileiros, que hoje dão nome a importantes instituições de pesquisa, como Oswaldo Cruz e Emílio Ribas, tiveram seus nomes inscritos na história da saúde pública como líderes do combate à febre amarela. A doença ganhou significado simbólico relevante no país e faz parte do repertório coletivo de assombrações nacionais. A última epidemia de febre amarela urbana no Brasil foi considerada encerrada em $1942^{5}$.

O que temos hoje, diferentemente das epidemias do passado, é a febre amarela silvestre, com números excepcionalmente altos. As diferenças entre a forma urbana da doença e a silvestre estão no ciclo de transmissão e na ocorrência de cada uma como fato social. Quanto ao agente infeccioso - o vírus - e à fisiopatologia, a doença é uma só.

São eventos ecossociais diferentes. Quando circula nas florestas, áreas rurais e franjas urbanas adjacentes a elas, o vírus é enzoótico entre primatas que ali habitam, ou seja, mantém-se em circulação continuamente onde há contato frequente entre mosquitos transmissores, macacos com o vírus e outros que nunca foram infectados. Nesses casos, há animais que sobrevivem à doença e ficam imunes, outros morrem e, enquanto houver suscetíveis em quantidade suficiente, o vírus continua presente, persistindo por longos períodos em extensos ecossistemas. Quando um bando sem imunidade é atingido, um grande número de animais adoece, caracterizando uma epizootia, equivalente, entre os animais, às epidemias em populações humanas. Nessas ocasiões, é frequente o achado de macacos mortos, o que é um alerta para a possibilidade de que o vírus esteja com circulação intensa naquela localidade. Essa sucessão de eventos dá um comportamento periódico às ocorrências, com ciclos de aumentos de casos em intervalos que são imprecisos, pois é grande a heterogeneidade dos fatores que interagem para aumentar a transmissão. Quando começa uma epizootia, os macacos costumam se deslocar e o vírus pode acompanhá-los.

As pessoas entram no ciclo se visitarem ou frequentarem as áreas onde a transmissão está ativa, vitimadas, assim, pela febre amarela silvestre.

Não é possível identificar causas para o quadro atual. O componente cíclico tem sua importância; provavelmente, a ocupação de áreas de mata com atividades econômicas também, assim como variações climáticas e outras interferências ambientais. Fato é que, ao longo dos anos, em regiões silvestres e rurais onde não havia febre amarela, hoje há, e a velocidade de expansão cresceu nos últimos anos, chegando muito perto de grandes metrópoles.

A associação entre a morte de macacos e a ocorrência da doença tem levado, em muitas ocasiões, à crença de que eles disseminam a febre amarela, resultando inclusive em agressões a esses animais. Assim, é importante lembrar sempre, que os macacos não transmitem a doença, mas sim os mosquitos. O lugar dos macacos no ciclo da febre amarela é equivalente ao dos humanos. Mais do que isso, quando estão presentes os macacos, a vigilância de doenças e mortes entre eles é um dos mecanismos mais importantes para a detecção precoce da circulação do vírus em uma localidade, permitindo a resposta rápida para evitar casos humanos ${ }^{6}$.

Há um grande medo de que a doença volte a se urbanizar. Isso poderia acontecer caso uma pessoa com o vírus permanecesse em local com grande infestação do vetor urbano. Seria praticamente inevitável, se não houvesse a vacina; ela é o único instrumento existente capaz de evitar o cenário temido. Caso se consiga vacinar as pessoas expostas a risco, será muito improvável o registro de casos humanos.

Com a turbulência do tema, informações falsas têm circulado intensamente, entre elas, as que questionam a eficácia, a segurança ou a qualidade das vacinas. Isso não é uma novidade na saúde pública. Nem todos 
precisam receber a vacina contra a febre amarela. Ela é essencial para quem frequenta áreas de mata ou suas proximidades. Ela não é importante para pessoas que vivem em regiões densamente edificadas, distantes de matas e têm certeza de que não vão se deslocar. A disseminação de mentiras sobre o imunizante dificulta a melhoria das coberturas vacinais.

A área de vacinas é alvo constante de inverdades. Um dos casos mais escandalosos de fraude científica aconteceu justamente quando um pesquisador britânico - Andrew Wakefield - publicou, com outros doze autores, um artigo na importante revista Lancet, em que afirmava uma correlação causal entre a vacina tríplice viral (contra rubéola, sarampo e caxumba) e a ocorrência de autismo ${ }^{7}$. Anos depois, foi constatado que a pesquisa era fraudulenta, o que motivou uma retratação pela revista e a cassação do registro médico do autor na Inglaterra. Investigações concluíram que havia relevantes interesses econômicos envolvidos ${ }^{8}$. No entanto, o estrago foi feito; muitas crianças deixaram de receber a vacina, em especial na Europa, por causa da boataria. A ação, que poderia ser chamada de criminosa, contribuiu para a ocorrência de surtos de sarampo, com internações e mortes.

Convicções filosóficas ou religiosas podem motivar a difusão de orientações, cujos efeitos sobre a saúde são nefastos. É conhecida, por exemplo, a dificuldade de manter boas coberturas vacinais na chamada "faixa da bíblia”, na Holanda, onde se concentram protestantes ortodoxos que se opõem à vacinação. Nessa área, nos anos de 2013 e 2014 foram registrados 2.700 casos de sarampo, uma grande epidemia que poderia ter sido prevenida com a vacinação9 . Relatos semelhantes acontecem entre pessoas de afiliação antroposófica, entre outras.

O Instituto Biomanguinhos, da Fiocruz, no Brasil, é o maior produtor mundial da vacina contra a febre amarela, a mais antiga entre as oferecidas atualmente pelo Sistema Único de Saúde, cujos resultados já puderam ser muito bem conhecidos em longos tempos de observação. Dos que recebem a vacina, entre 90\% e 98\% tornam-se imunes de sete a dez dias depois. Por isso, é importante recebê-la pelo menos dez dias antes de entrar em área com risco de transmissão. O esquema vacinal adotado atualmente em todo o mundo prevê uma única dose de vacina ao longo da vida. Em algumas situações de escassez do produto, tem sido utilizada a vacina fracionada, com um quinto da dose convencional; os estudos realizados mostram que essa formulação é capaz de proteger como a vacina original, por pelo menos oito anos ${ }^{10}$. A orientação completa é divulgada pelo Ministério da Saúdei.

Vários tipos de interesse podem levar à difusão de mentiras no campo da saúde pública. Foram mencionados motivos políticos, financeiros, religiosos e filosóficos; podem haver outros. Importante é que a informação adequada chegue oportunamente às pessoas de forma que elas confiem. $O$ fortalecimento das instituições de saúde, de ensino e pesquisa, com investimento em suas interfaces de comunicação pode contribuir para que sejam reconhecidas como fonte de consulta para profissionais e a população. Campanhas de orientação podem ser úteis. Entretanto, como a população mais exposta a risco quase não tem acesso à mídia, vivendo de forma intermitente ou contínua fora das cidades, o trabalho ativo de campo, sob responsabilidade de equipes de saúde familiarizadas e conhecidas nas localidades, levando informações e administrando vacinas, deve ser a grande prioridade para interromper a epidemia atual e melhorar o conhecimento público sobre a doença.

i A proteção possivelmente é vitalícia, mas os estudos fizeram seguimento por oito anos, até o momento. 


\section{Referências}

1. Malinverni C. Uma doença, duas notícias: a febre amarela nos governos Lula e Temer. Observatório do Direito à Comunicação [Internet]; 2017 Jul [citado em 2018 mar. 23]. Disponível em: http://www. intervozes.org.br/direitoacomunicacao/?p=29956

2. Brasil, Ministério da Saúde. Febre amarela: Ministério da Saúde atualiza casos no país. Boletim Epidemiológico. Brasília, DF: Ministério da Saúde; 2018Mar [citado em 2018 mar. 22]. Disponível em: http://portalms.saude.gov.br/noticias/agencia-saude/42857-febre-amarela-ministerio-da-saude-atualizacasos-no-pais-4

3. Ferreira KV, Rocha KC, Caputto LZ, Fonseca ALA, Fonseca FLA. Histórico da febre amarela no Brasil e a importância da vacinação antiamarílica. Arq Bras Ciênc Saude; 2011 jan./abr. [citado em 2018 mar. 27];36(1):40-7. https://doi.org/10.7322/abcs.v36i1.74

4. Menezes M. Conheça semelhanças e diferenças entre mosquitos transmissores da febre amarela. Comunicação e informação - Notícias. Rio de Janeiro: Fiocruz; 2017 [citado em 2018 mar. 26]. Disponível em: https://portal.fiocruz.br/noticia/conheca-semelhancas-e-diferencas-entre-mosquitostransmissores-da-febre-amarela

5. Benchimol JL. História da febre amarela no Brasil. Hist. cienc. saúde-Manguinhos. 1994;1(1):121-4. http://dx.doi.org/10.1590/S0104-59701994000100010

6. Brasil. Ministério do Meio Ambiente. Macacos não transmitem febre amarela. Brasília, DF: Ministério do Meio Ambiente; 2018 [citado em 2018 mar. 26]. Disponível em: http://www.mma.gov.br/index.php/ comunicacao/agencia-informma?view=blog\&id $=2814$

7. Wakefield AJ, Murch SH, Anthony A, Linnell J, Casson DM, Malik M et al. Ileal-lymphoid-nodular hyperplasia, non-specific colitis, and pervasive developmental disorder in children. The Lancet. 1998;351(9103):637-41. https://doi.org/10.1016/S0140-6736(97)11096-0. Retracted article [artigo invalidado por meio de retratação].

8. Harris G. Journal Retracts 1998 Paper Linking Autism to Vaccines. The New York Times. Feb. 2, 2010 [citado em 2018 mar. 27]. Disponível em: https://www.nytimes.com/2010/02/03/health/ research/03lancet.html

9. Woudenberg T, Binnendijk RS, Sanders EAM, Wallinga J, Melker HE, Ruijs WLM et al. Large measles epidemic in the Netherlands, May 2013 to March 2014: changing epidemiology. Euro Surveill. Jan 2017 [citado em 2018 mar. 27];22(3):30443. https://doi.org/10.2807/1560-7917.ES.2017.22.3.30443

10. Brasil. Ministério da Saúde. Febre amarela: guia para profissionais de saúde. Brasília, DF: Ministério da Saúde; 2018 [citado em 2018 mar. 23]. Disponível em: http://portalarquivos2.saude.gov.br/images/ pdf/2018/janeiro/18/Guia-febre-amarela-2018.pdf 